\title{
Analysis of Soluble Molecular Fibronectin-Fibrin Complexes and EDA-Fibronectin Concentration in Plasma of Patients with Atherosclerosis
}

\author{
Anna Lemańska-Perek, ${ }^{1,3}$ Dorota Krzyżanowska-Goląb, ${ }^{1}$ Małgorzata Pupek, ${ }^{1}$ Piotr Klimeczek, ${ }^{2}$ \\ Wojciech Witkiewicz, ${ }^{2}$ and Iwona Kątnik-Prastowska ${ }^{1}$
}

\begin{abstract}
Atherosclerosis, a chronic vascular disease, leads to molecular events bound with interplaying processes of inflammation and coagulation. In the present study, fibronectin (FN), FN containing extra domain A (EDA-FN), frequency of occurrence, and relative amounts of soluble plasma FN-fibrin complexes were analyzed in 80 plasma samples of patients suspected of coronary artery disease based on clinical evaluation and changes in arteries found by computed tomographic coronary angiography. The study showed that in the plasma of the patients' group with high risk of coronary artery disease EDA-FN concentration was significantly higher $(3.5 \pm 2.5 \mathrm{mg} / \mathrm{L} ; P<0.025)$ and the molecular FN-fibrin complexes of $1000 \mathrm{kDa}$ and higher occurred more often than in the groups of patients with mild risk of coronary artery disease and the normal age-matched. The increased level of EDA-FN and occurrence of FN-fibrin complexes could have a potential diagnostic value in the diagnosis and management of patients with coronary artery disease.
\end{abstract}

KEY WORDS: fibronectin; fibronectin bearing EDA segment; FN-fibrin complexes; atherosclerosis.

\section{INTRODUCTION}

Development of atherosclerotic lesions, which increasingly affect the human population, causing high morbidity and mortality, are known to be associated with chronic inflammation and can lead to thrombosis and diverse cardiovascular diseases [1]. At the cellular and molecular levels, atherosclerosis is known to activate immune-inflammatory pathways, encompassing multiple complex interdependent interactions among inflammatory cells, vascular elements, extracellular matrix molecules, and plasma proteins through expression of cytokines, and

\footnotetext{
${ }^{1}$ Department of Chemistry and Immunochemistry, Medical University of Wrocław, Bujwida 44a, 50-345 Wrocław, Poland

${ }^{2}$ Provincial Specialist Hospital in Wrocław, Research and Development Center in Wrocław, Wrocław, Poland

${ }^{3}$ To whom correspondence should be addressed at Department of Chemistry and Immunochemistry, Medical University of Wrocław, Bujwida 44a, 50-345 Wrocław, Poland. E-mail: anna.lemanskaperek@umed.wroc.pl
}

several adhesion molecules and their receptors [2-4]. The atheroprogression is manifested by the development of atheromatous plaque in the affected vessel wall, which leads to diverse vascular lesions and disturbs molecular vessel functions, vascular permeability, and flow of blood around the body $[2,3,5]$.

A key event associated with plaque formation is expansion and remodeling of extracellular matrix components (ECM) in susceptible arterial areas [6].

During atherosclerotic lesions under diseasedependent conditions, the normal complex organization of ECM undergoes harmful structural and functional modifications which can lead to the occurrence of numerous diseases [6-8]. Among the major proteins of ECM responsible for the organization and regulation of ECMdependent molecular functions, a multifunctional and multidomain glycoprotein, fibronectin (FN), plays a crucial role [8-10]. FN, besides being an insoluble component of ECM and tissues (cFN), is also an abundant protein of plasma and other physiological fluids. In plasma and 
tissues, FN can exist in diverse isoforms arising from posttranslational modifications ( $\mathrm{N}$ - and O-glycosylation, phosphorylation), alternative splicing of FN premessenger RNA (i.e., inclusion of EDA, EDB, and IIICS segments), and moreover from variable conformations depending on environmental conditions (globular and fibrillar structures) $[8,9,11]$.

FN is a large dimeric glycoprotein $(450-500 \mathrm{kDa})$; each monomer of which consists of types I, II, and III of repeating amino acid units. The multiple copies of repeats are arranged into several domains able to bind fibrin, collagen, glycosaminoglycans, and cellular receptors [9, 10]. Two identical or nearly identical (depending on the included or excluded spliced extra domains) FN polypeptides are linked together by two disulfide bonds near their carboxyl termini. In contrast, their $\mathrm{N}$-termini ends are unlinked, facilitating formation of many diverse conformational structures able to react with FN ligands $[9,11]$. Its hepatic origin, plasma form of $\mathrm{FN}(\mathrm{pFN}$ ) lacking extra EDA and EDB segments, has a looped compact conformation which can be stretched to an unfolded conformation when $\mathrm{FN}$ is caught by cellular integrin receptors $[9,11]$. The tissue cellular FN (cFN) is synthesized by many cell types (e.g., fibroblasts, endothelial cells, platelets, and monocytes) and bears variable proportions of EDA and EDB segments (EDA-FN and EDB-FN, respectively) [9, 12].

Both forms, $\mathrm{pFN}$ and $\mathrm{cFN}$, are reported to be incorporated into the fibrillar network of ECM $[9,10,13]$, where they play structural and functional roles regulating some cellular activities $[9,14]$. The plasma-derived FN is reported to support hemostasis, regulate thrombosis $[15,16]$, and significantly accelerate healing, reducing the area of inflammation [17, 18]. Plasma FN is also a major component of the blood clot. With fibrin and its degraded forms, it readily forms a macromolecular complex which can be cross-linked covalently in the reaction catalyzed by transglutaminase XIIIa [16, 19]. Through binding with fibrin, $\mathrm{pFN}$ influences the rate of formation, stability, as well as the structure of the fibrin matrix $[15,20]$.

In spite of the fact that both EDA- and EDB-FN isoforms take part in vasculogenesis in embryos and angiogenesis in cancer and non-tumoral conditions, the specific integrin receptors have been identified exclusively for EDA-FN [12, 21, 22]. FN carrying the EDA segment recognized by integrin receptors is reported to be implicated in efficient adhesion, activation, and aggregation of platelets, promoting in that way inflammation and coagulation processes [23-25]. The initial step of platelet adhesion is immobilization of dimeric EDA-FN on platelets by integrins $\alpha 5 \beta 1$ and $\alpha \operatorname{IIb} \beta 3$ and stretching of a dimeric cFN to its fibrillar form. Maurer et al. [2015] provided experimental evidence that a fibrillar form of EDA-FN is a potent thrombogenic component of the subendothelium. The interaction of immobilized fibrillary EDA-FN to platelet integrins together with glycoprotein Ib-V-IX complex, a major signaling receptor for collagen, and Toll-like receptor 4 initiates molecular reactions which lead to activation of the coagulation cascade and promotion of thrombus formation [23]. These events bring a high risk of atherosclerosis and thrombosis development [16, 26-28].

On the other hand, EDA-FN located on the top of a plaque is known to form a protective fibrous cap, which prevents plaque rupture and vascular occlusion $[26,29-$ 31].

In the present study, frequency of occurrence and relative amounts of soluble plasma FN-fibrin complexes were determined in plasma of patients suspected of coronary artery disease based on significant changes observed in the patients' artery. The relative amounts of soluble plasma FN-fibrin complexes were analyzed with respect to FN and EDA-FN concentrations, occurrence of FN monomer, and eventual presence of FN fragments. The FN and EDA-FN concentrations were estimated by ELISA with two specific monoclonal antibodies, and the occurrence and relative amounts of FN-fibrin complexes and FN monomer and possible presence of FN degradation products were analyzed by SDS-agarose immunoblotting [32] and Western blotting [33], respectively. The study indicates that the analysis of FN-fibrin complexes and the EDA-FN concentration can help to better understand the mechanisms underlying thrombosis and changes associated with endothelial dysfunction and vascular diseases.

\section{MATERIALS AND METHODS}

\section{Patients}

Patients were included in the study after their clinical evaluation was performed and informed consent had been given. The study was approved by the Bioethical Committee at the Regional Specialist Hospital in Wroclaw and complies with the 1975 Declaration of Helsinki.

Participants $(n=80,39$ women and 41 men, aged $63.8 \pm 9$ years) were recruited to the study from persons attending the Emergency Department of the Regional Specialized Hospital in Wroclaw because of chest pain and inconclusive unstable angina pectoris detection by classical 
tests such as high-sensitive troponin I (hsTnI) and electrocardiography (ECG).

After hospitalization, the patients suspected of coronary artery disease (CAD), but with myocardial infarction excluded, were included in the study based on standard computed tomographic coronary angiography (CTCA) performed as describe previously by Miszalski-Jamka et al. [34]. CTCA was performed using a $2 \times 32$-slice Dual Source Computed Tomography Scanner (Somatom Definition, Siemens, Erlangen, Germany). Images were reconstructed using a B26f kernel with an image matrix of $512 \times 512$ pixels. A multiphase reconstruction (from 0 to $90 \%$ ) was performed and the best quality image reconstructions were assessed. The post processing and study evaluation were performed using a dedicated workstation (3D Leonardo, Syngo Via Siemens Medical Solution, Erlangen, Germany).

\section{Sampling}

Blood samples (4.5 ml), anti-coagulated with $3.2 \%$ sodium citrate $(0.5 \mathrm{ml})$, were collected from 80 patients suspected of CAD and plasma was immediately separated from the blood cells by centrifugation at $2000 \times g$ for $10 \mathrm{~min}$. The samples were aliquoted and stored at $-76{ }^{\circ} \mathrm{C}$ until analysis.

Eighty patients' samples were divided into groups 1 and 2 according to the degree of vessel lumen narrowing caused by arteriosclerotic plaque distinguished based on the data of computed tomographic coronary angiography [34]. Group 1 with significant coronary artery changes comprised 66 plasma samples of patients (30 females and 36 males; mean age $64.4 \pm 9$ years) with presence of atherosclerotic plaques in the coronary arteries and with one or more visible stenosis ( $>50 \%$ vessel lumen narrowing). Group 2 with mild coronary artery changes comprised 14 blood plasma samples of patients ( 9 females and 5 males; mean age $61.5 \pm 9$ years $)$ with $(<50 \%$ vessel lumen narrowing) or without visible vessel lumen narrowing. The characteristics of the blood parameters of patients are summarized in Table 1.

The control group comprised samples taken from healthy non-smoking volunteers ( 13 females and 8 males; mean age $65.3 \pm 12$ years), members of the Wrocław Medical University staff, and 8 people who visited the emergency department because they felt a pain in the chest, but based on the results of CTCA and normal values of routine laboratory blood parameters were included in the control group.

\section{FN Concentration}

Plasma FN (pFN, test 1) and EDA-FN (test 2) concentrations were determined by two independent ELISAs using a well-defined domain-specific monoclonal antibody directed to a centrally located comprehensive cell-binding domain of FN (FN30-8; M010 TaKaRa Shuzo Co. Ltd., Shiga, Japan) [32] or to an extra domain EDA of FN (DH1, EMD Millipore, Merck KGaA Darmstadt, Germany). The monoclonal antibodies anti-FN (test 1) and anti-EDA-FN (test 2), diluted 1:10 000 and 1:3000, respectively, in TBS, were used as a coating agent in the wells of a microtiter plate (Nalge Nunc International, Naperville, IL, USA) to bind FN and EDA-FN in the samples. The amount of FN bound by the monoclonal antibody was quantified by rabbit anti-FN polyclonal antibodies (Sigma Chemical Co, St Louis, MO, USA, diluted 1:5000 (test 1), or 1:2500 (test 2) in TBS containing $0.1 \%$ Tween-20) and peroxidase-conjugated goat anti-rabbit immunoglobulins (Sigma Chemical Co, St Louis, MO, USA), diluted $1: 20,000$ (test 1 ), or 1:3000 (test 2) as the secondary antibodies. The amount of FN was assayed by a colorimetric reaction using o-phenylenediamine dihydrochloride/ $\mathrm{H}_{2} \mathrm{O}_{2}$ as the enzyme substrate and measured in a Stat Fax 2100 Microplate Reader (Awareness Technology Inc, Palm City, FL, USA) at $450 \mathrm{~nm}$ with $630 \mathrm{~nm}$ as a reference filter. The samples were analyzed in two different sample dilutions, each in duplicate. The $\mathrm{pFN}$ and EDA-FN concentrations are given in milligram per liter and presented as the mean \pm standard deviation (SD).

To determine non-specific binding, two controls were included in the tests: minus primary antibody and minus secondary antibody.

A human plasma FN preparation (Sigma, St. Louis, MO, USA, from 2.5 to $50 \mathrm{ng} /$ well) was used as a standard for FN-ELISA determination (test 1), and acellular fibronectin from human foreskin fibroblasts (Sigma, St. Louis, MO, USA, from 3.125 to $50 \mathrm{ng}$ /well) for EDA-FN-ELISA (test 2).

\section{Western Immunoblotting}

Plasma samples containing $300 \mathrm{ng}$ of FN were subjected to SDS- $(10 \%)$ polyacrylamide gel electrophoresis under reducing conditions as described earlier [35].

\section{SDS-Agarose FN Immunoblotting}

Plasma FN-fibrin complexes were revealed by SDSagarose immunoblotting as described previously [32]. 
Table 1. Biochemical Characteristics of the Groups of Patients with Atherosclerosis

\begin{tabular}{|c|c|c|c|c|}
\hline \multirow{2}{*}{$\begin{array}{l}\text { Parameter } \\
\text { Number of samples } \\
\text { female/male } \\
\text { age, years }\end{array}$} & \multicolumn{4}{|l|}{ Groups } \\
\hline & \multicolumn{2}{|c|}{$\begin{array}{l}\text { 1. Significant } \\
\text { coronary artery } \\
\text { changes } \\
n=66 \\
30 / 36 \\
64.4 \pm 9\end{array}$} & \multicolumn{2}{|c|}{$\begin{array}{l}\text { 2. Mild coronary artery } \\
\text { changes } \\
n=14 \\
9 / 5 \\
61.5 \pm 9\end{array}$} \\
\hline $\begin{array}{l}\text { Total cholesterol } \\
\mathrm{mg} / \mathrm{dL}\end{array}$ & $\begin{array}{l}200.5 \pm 5 \\
195 \\
(162-237 \\
30 \uparrow\end{array}$ & & $\begin{array}{l}198.2 \pm 39.2 \\
204 \\
(167-212) \\
7 \uparrow\end{array}$ & \\
\hline $\begin{array}{l}\mathrm{HDL} \\
\mathrm{mg} / \mathrm{dL}\end{array}$ & $\begin{array}{l}\text { Female } \\
56.8 \pm \\
\quad 26.7 \\
52.5 \\
(46-64) \\
7 \downarrow\end{array}$ & $\begin{array}{l}\text { Male } \\
59.4 \pm \\
\quad 49.1 \\
45 \\
(40-53)\end{array}$ & $\begin{array}{l}\text { Female } \\
55.3 \pm 13.4 \\
51.5 \\
(46.5-62.5) \\
2 \downarrow\end{array}$ & $\begin{array}{l}\text { Male } \\
52.6 \pm 31.3 \\
41 \\
(36-45) \\
2 \downarrow\end{array}$ \\
\hline $\begin{array}{l}\mathrm{LDL} \\
\mathrm{mg} / \mathrm{dL}\end{array}$ & $\begin{array}{l}122.1 \pm 4 \\
118 \\
(82-153) \\
40 \uparrow\end{array}$ & & $\begin{array}{l}115.9 \pm 22.2 \\
107 \\
(105-119) \\
10 \uparrow\end{array}$ & \\
\hline $\begin{array}{l}\mathrm{BMI} \\
\mathrm{kg} / \mathrm{m}^{2}\end{array}$ & $\begin{array}{l}26.6 \pm 5 . \\
27.7 \\
(24.1-29\end{array}$ & & $\begin{array}{l}26.6 \pm 8.1 \\
26 \\
(25.4-32)\end{array}$ & \\
\hline $\begin{array}{l}\text { Glucose } \\
\mathrm{mg} / \mathrm{dL}\end{array}$ & $\begin{array}{l}108.6 \pm 3 \\
104 \\
(94-115) \\
36 \uparrow\end{array}$ & & $\begin{array}{l}130.5 \pm 50.4 \\
109 \\
(97-175) \\
10 \uparrow\end{array}$ & \\
\hline $\begin{array}{l}\text { CRP } \\
\mathrm{mg} / \mathrm{L}\end{array}$ & $\begin{array}{l}3.6 \pm 3.9 \\
2 \\
(0.95-5.7 \\
16 \uparrow\end{array}$ & & $\begin{array}{l}4.6 \pm 7.4 \\
2.15 \\
(0.97-4.55) \\
3 \uparrow\end{array}$ & \\
\hline $\begin{array}{l}\text { hsTnI } \\
\mathrm{ng} / \mathrm{ml}\end{array}$ & $\begin{array}{l}<0.04 \\
(0.09 \pm 0 \\
11 \uparrow\end{array}$ & & $<0.04$ & \\
\hline
\end{tabular}

Values of blood parameters are given as mean values $\pm \mathrm{SD}$, median, and (25th and 75th) quartiles. $\uparrow \downarrow$ the number of samples with low ( $\downarrow$ ) or high $(\uparrow)$ value. All parameters were determined using routine laboratory techniques. All biochemical parameters were determined with commercial kits, and CRP levels were measured with a coagulometer

$H D L$ high-density lipoprotein, $L D L$ low-density lipoprotein, $B M I$ body mass index, $C R P$ C-reactive protein, $h s T n I$ high-sensitive troponin I (TnI was measured twice, at the time of admission to an emergency department and $6 \mathrm{~h}$ after)

\section{Statistics}

Data are presented as means \pm standard deviations (SD). Comparisons between groups were performed by means of the Kruskal-Wallis and post hoc tests. $P$ values less than 0.05 were regarded as significant.
Receiver operating characteristic (ROC) analysis was performed with R for Windows (the R Foundation for Statistical Computing, Vienna, Austria).

To estimate the usefulness of the FN-fibrin complexes and EDA-FN for differential diagnostics of the state of patients with significant coronary artery changes compared to mild coronary artery changes, statistic cluster analysis was used (Statistica version 12 PL, StatSoft Inc., Tulsa, OK, USA). The results are presented as a dendrogram, starting with all the subjects (patients and controls) in one cluster, finally leading to separate clusters as leaves of a binary tree.

\section{RESULTS}

\section{Plasma FN Concentration}

The mean values of pFN concentration (Fig. 1a) were similar in patient group 1 with significant coronary artery changes $(292.53 \pm 74.4 \mathrm{mg} / \mathrm{L})$ and group 2 with mild coronary artery changes $(280.21 \pm 90.9 \mathrm{mg} /$ L), but slightly higher than in the control group $(253.38 \pm 82.3 \mathrm{mg} / \mathrm{L})$.

\section{EDA-FN Concentration}

Compared with the control group $(2.0 \pm 0.7 \mathrm{mg} / \mathrm{L})$, the mean EDA-FN concentration (Fig. 1b) was significantly higher in group $1(3.5 \pm 2.5 \mathrm{mg} / \mathrm{L} ; P<0.025)$ and at a similar level in group $2(2.4 \pm 1.9 \mathrm{mg} / \mathrm{L})$.

The ROC curve analysis of EDA-FN concentration (Fig. 3a) showed a sensitivity of $53 \%$ and specificity of $91 \%$ (area under the curve [AUC] 0.67).

\section{FN Fragments}

The electrophoresis of plasma samples in $10 \%$ polyacrylamide gel under reducing conditions and subsequent immunoblotting with anti-FN monoclonal antibody did not show the presence of FN fragments.

\section{Occurrence of FN-Fibrin Complexes}

SDS-agarose immunoblotting revealed the presence, beside bands corresponding to FN dimer $(500 \mathrm{kDa})$ and FN monomer ( $250 \mathrm{kDa})$, of FN-fibrin bands with decreasing electrophoretic mobilities (Table 2, Fig. 2) and increasing molecular masses of 750,1000,1300,1600, 1900, and $2200 \mathrm{kDa}$. The FN-fibrin bands were numbered as FNfibrin complexes I-VI, respectively. 

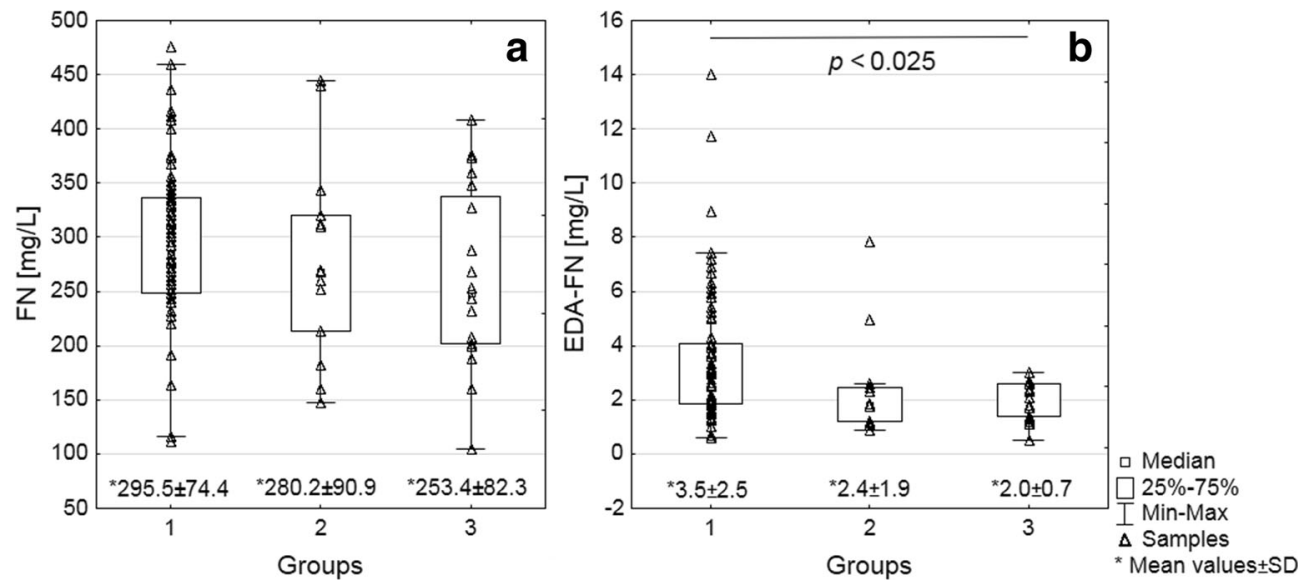

Fig. 1. Distribution of FN (a) and EDA-FN (b) concentrations in plasma of patients with atherosclerosis. pFN (a) and EDA-FN (b) concentrations were determined by ELISA [35], using two monoclonal antibodies domain-specific directed to cell-binding domain of FN (FN30-8; M010 TaKaRa Shuzo Co. Ltd., Shiga, Japan) and EDA segment of FN (EMD Millipore, Merck KGaA Darmstadt, Germany). For details see "Materials and Methods." Data are given as mean values $\pm \mathrm{SD}$, median, and (25th and 75th) quartiles. Significantly different from the age-matched normal group calculated by the Kruskal-Wallis and post hoc tests.

The plasmas of group 1 (significant changes in the coronary artery) contained the set of $\mathrm{FN}$-fibrin complexes I-VI whose frequency of occurrence (from 0.83 for complex I to 0.03 for complex VI) and their relative amounts (from $28.3 \%$ for complex I to $4.4 \%$ for complex VI) decreased with the increased molecular mass of the FNfibrin complexes. In contrast, the plasma of group 2 (mild coronary artery changes) and age-matched controls, beside the FN-fibrin complex I occurring in about $70 \%$ of samples, contained none of the detectable FN-fibrin complexes II-VI, excluding one sample of group 2, which revealed the presence of complex II. Moreover, the mean relative amount of FN-fibrin complex I $(13.36 \pm 10.2 \%)$ was higher in group 1 than in group $2(7.25 \pm 6.7 \%)$ and the control group $(6.88 \pm 4.6 \%)$.

ROC curve analysis of the relative amounts of FNfibrin complexes ( $\sim 750$ and $\sim 1000 \mathrm{kDa})$ identified parameters with a sensitivity of $53 \%$ and specificity of $88 \%$ (AUC 0.67) for complex I (Fig. 3b) and a sensitivity of $39 \%$ and specificity of $97 \%$ (AUC 0.68 ) for complex II (Fig. 3c).

Cluster analysis (Fig. 4) based on the relative amounts of FN-fibrin complexes and EDA-FN concentration data of groups 1,2, and the age-matched group allowed the cluster A samples $(n=21,32 \%)$ from group 1 to be separated from the rest of the samples (cluster B).

The analysis for atherosclerosis risk factors (total cholesterol, LDL, HDL, BMI, CRP, glucose level, sex, and age) showed that the samples from cluster A have slightly higher levels of HDL and LDL (62.2 \pm 50.4 and $130.6 \pm 45.9$, respectively) compared to the rest of the patients from the group of significant coronary artery changes $(56.1 \pm 33.8$ and $117.8 \pm 44.4$, respectively). Moreover, the patients in this subgroup were significantly younger (mean age $60.4 \pm 8$ years, $P<0.022$ ) than the rest of patients in this group (mean age $66 \pm 9$ years).

\section{DISCUSSION}

The study showed that the presence of soluble FNfibrin complexes and high concentration of the $\mathrm{FN}$ isoform bearing an EDA segment (EDA-FN) in patients' plasma were associated with significant changes in the coronary artery, and these subjects were suspected of high risk of coronary artery disease (CAD) more often than in those with mild or no changes in blood vessels.

The high EDA-FN concentration (Fig. 2b) in the plasma samples of patients with high risk of CAD compared with its low level in the plasma of controls as well as patients with low risk of CAD (Fig. 2b) has also been observed by others in ischemic stroke [36], diabetes [37], atherosclerosis [30], and cancer [38]. EDA-FN occurrence in plasma at a high concentration is believed to be associated with inflammation and its release from tissues to the circulation during arterial wall lesions in thrombosis [39], plaque formation, development and progression of 
Table 2. Frequency of Occurrence and Relative Amount of Fn-Fibrin Complexes in Plasma of Patients with Atherosclerosis

\begin{tabular}{|c|c|c|c|c|}
\hline \multirow[t]{2}{*}{ Plasma FN forms } & \multirow[t]{2}{*}{$M_{\mathrm{m}}(\mathrm{kDa})$} & \multicolumn{3}{|c|}{$\begin{array}{l}\text { Frequency of occurrence and relative amount of } \mathrm{FN} \text { forms } \\
\text { in plasma groups } 1-3 \\
\text { Mean value of relative amount } \pm \mathrm{SD}\end{array}$} \\
\hline & & $\begin{array}{l}\text { 1. Significant coronary } \\
\text { artery changes } n=66\end{array}$ & $\begin{array}{l}\text { 2. Mild coronary artery } \\
\text { changes } n=14\end{array}$ & $\begin{array}{l}\text { 3. Age-matched normal } \\
\text { group } n=21\end{array}$ \\
\hline \multirow[t]{2}{*}{ FN monomer \pm degradations fragments } & \multirow[t]{2}{*}{$\sim 250$} & $0.94(62)$ & $0.92(14)$ & $0.85(18)$ \\
\hline & & $6.24 \pm 3.4$ & $6.0 \pm 3.2$ & $4.95 \pm 4.5$ \\
\hline \multirow[t]{2}{*}{ FN dimer } & \multirow[t]{2}{*}{$\sim 500$} & $1(66)$ & $1(14)$ & $1(21)$ \\
\hline & & $74.66 \pm 17.7$ & $86.33 \pm 8.5$ & $88.13 \pm 7.5$ \\
\hline \multirow[t]{13}{*}{ FN-fibrin complexes } & I & $0.83(55)$ & $0.64(9)$ & $0.76(16)$ \\
\hline & $\sim 750$ & \multicolumn{2}{|l|}{$P<0.048$} & $6.88 \pm 4.6$ \\
\hline & II & $0.39(26)$ & $0.07(1)$ & Not \\
\hline & \multirow[t]{2}{*}{$\sim 1000$} & $2.95 \pm 4.6$ & $0.19 \pm 0.7$ & detected \\
\hline & & $P<0.019$ & ${ }^{\mathrm{a}} 2.7$ & \\
\hline & III & $0.28(19)$ & Not & Not \\
\hline & $\sim 1300$ & $1.62 \pm 3.3$ & Detected & Detected \\
\hline & IV & $0.2(13)$ & Not & Not \\
\hline & $\sim 1600$ & $0.77 \pm 2.1$ & detected & detected \\
\hline & $\mathrm{V}$ & $0.05(3)$ & Not & Not \\
\hline & $\sim 1900$ & $0.21 \pm 1.0$ & detected & detected \\
\hline & VI & $0.03(2)$ & Not & Not \\
\hline & $\sim 2200$ & $0.08 \pm 0.6$ & detected & detected \\
\hline
\end{tabular}

Plasma FN forms were revealed by SDS-agarose immunoblotting (see Fig. 2). Frequency of occurrence is the ratio of the number of samples containing the FN form to the total number of samples. In parentheses are given the number of samples which revealed the respective FN band. The relative amount of the FN band is the percentage of the total number of pixels found in the electrophoresis path and is expressed as mean value \pm SD. Data are presented as mean values \pm SD. Significantly different from the age-matched normal group calculated by the Kruskal-Wallis and post hoc tests

${ }^{a}$ The relative amount for the sample from group 2 with mild coronary artery changes $(\sim 1000 \mathrm{kDa})$

atherosclerosis, and arterial aging [24, 26-28]. However, the high EDA level in plasma can also reflect other pathophysiological processes connected with reconstruction of ECM [37] which can mask the changes due to atherosclerosis [30]. On the other hand, pFN (lacking an EDA segment) level in the plasma samples of patients with high and low risk of CAD did not differ from that in the normal group (Fig. 1a), and its diagnostic usefulness has been reported to be controversial, being probably due to different exclusion criteria for patients and differential timing of FN measurements in relationships to disease [16].

The present work also revealed the presence of FNfibrin complexes of 750,1000,1300, and $1600 \mathrm{kDa}$ in some plasma samples of patients with a high risk of CAD (Table 2, Fig. 2), which were absent in the plasma of agematched patients and those with a low risk of CAD, though with the exception of the presence of the complex with the smallest molecular mass of $750 \mathrm{kDa}$. The presence of the set of the FN-fibrin complexes has been previously reported by our group for plasma of patients with some inflammatory diseases $[32,40]$. In contrast, none of them were found in plasma of young and middle aged healthy individuals, but the $750-\mathrm{kDa}$ complex occurred progressively with aging of individuals [32, 33, 41].

The occurrence of FN-fibrin complexes in plasma of patients seems to reflect molecular events connected with interplaying processes of inflammation, immunity, and coagulation (Fig. 5). When the coagulation process is activated by inflammatory agent/s, the plasma fibrinogen is converted to fibrin, which in contrast to untouched fibrinogen is able to form a complex with $\mathrm{pFN}$. The fibrils of FN-fibrin are rapidly deposited in the injured vessel wall as the first factor in the wave of hemostasis and clot formation. The cascade of reactions of the coagulation system is under control and the thrombus is dissolved by the fibrinolytic system. In consequence, the lesion in the blood vessel is repaired by the wound healing process [9]. However, any imbalance/ dysregulation between procoagulant/antifibrinolytic and anticoagulant factors may lead to hypercoagulation, destruction of vessels, thrombosis, and atherosclerosis (Fig. 3). Such a situation may happen in disease-dependent conditions and with aging [44]. 


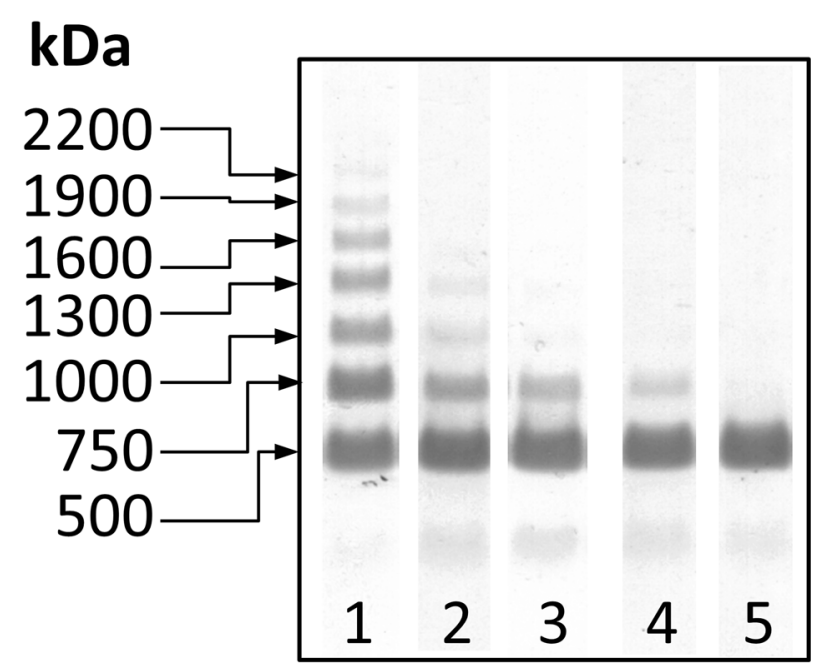

Fig. 2. Representative immunopatterns of FN-fibrin complexes in plasma samples of patients with atherosclerosis and age-matched normal group. The 101 blood plasma samples of atherosclerotic patients and age-matched normal individuals were subjected to SDS-agarose immunoblotting under non-reducing conditions [32]. For details see "Materials and Methods." Plasma samples: lanes 1-2, significant coronary artery changes; lane 3, mild coronary artery changes; lanes $4-5$, normal age-matched plasma. The molecular masses of the 750 to $2200 \mathrm{kDa}$ plasma FN-fibrin complexes and $500 \mathrm{kDa}$ FN dimer are shown by arrows on the left.

The FN-fibrin complexes are reported to play a different biological role than unbound $\mathrm{pFN}$ [15]. The pFNfibrin complex supports platelet aggregation and thrombosis and has prothrombotic activities [15, 42]. Moreover, Wang et al. (2014) reported that $\mathrm{pFN}$ through interactions with fibrin is able to switch from supporting hemostasis to inhibiting thrombosis/vessel occlusion, depending on the

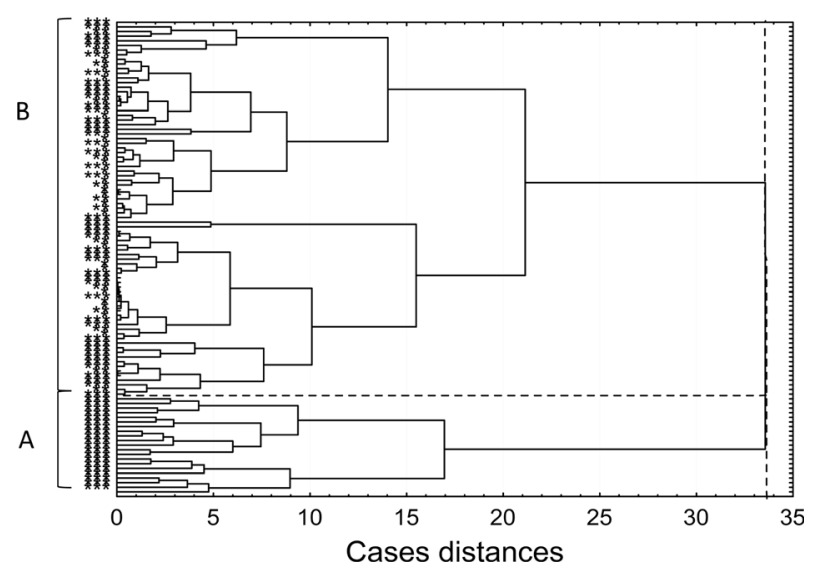

Fig. 4. Dendrogram of cluster analysis based on the data of FN-fibrin complexes and EDA-FN levels of human blood plasma samples of atherosclerotic patients and age-matched normal individuals. Triple asterisks indicate significant coronary artery changes, double asterisks mild coronary artery changes, and asterisk normal age-matched plasma. Cluster A and cut-off lane governing patients with significant coronary artery changes from the rest of samples with significant or mild coronary artery changes and controls (cluster B).

gradient of fibrin, and indicate that fibronectin is a selflimiting regulator in thrombosis [15].

Interestingly, the relative amounts of the FN-fibrin complexes did not show any correlation with the plasma EDA-FN concentration. The high concentration of EDAFN probably reflects progression of the atherogenic lesion, whereas the presence of FN-fibrin complexes in high amounts contributes to the hypercoagulation state (Fig. 5), although to a variable degree. The profile of FN-fibrin macro-complexes composed of the ladder of bands with
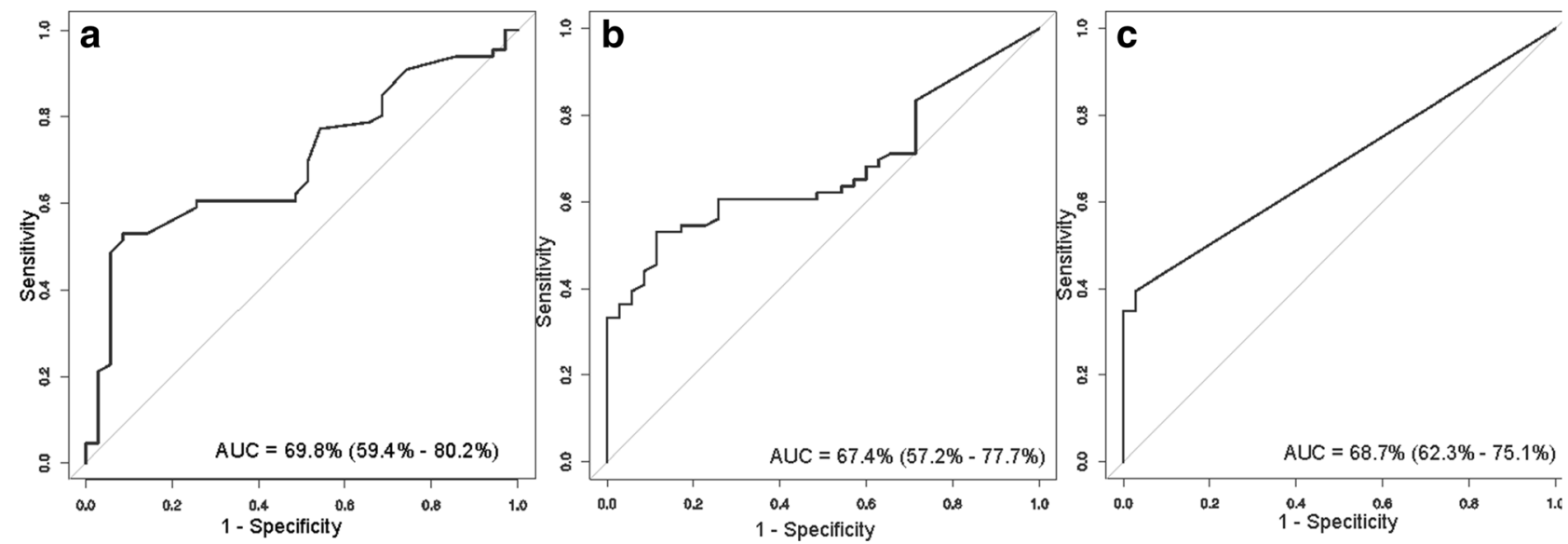

Fig. 3. ROC curves for values of EDA-FN concentration (a) and FN-fibrin complexes I (b) and II (c) relative amounts in plasma of patients with atherosclerosis. Data are given as AUC with $95 \%$ confidence interval. 


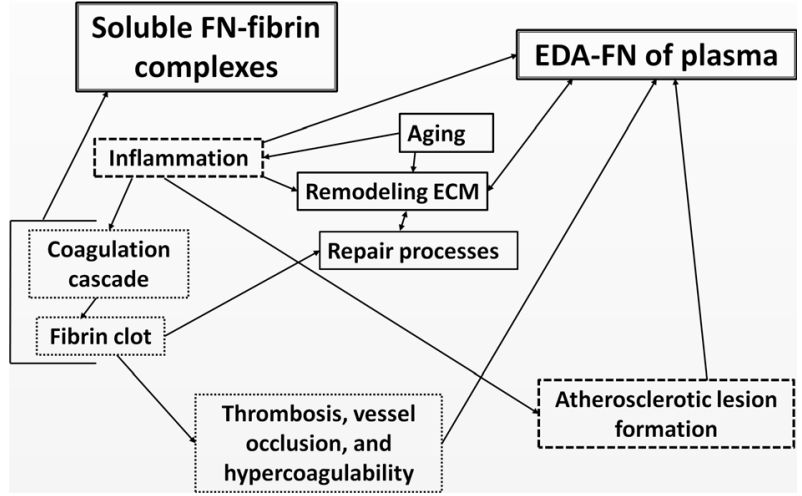

Fig. 5. The role of EDA-FN and FN-fibrin complexes in atherosclerosis. The released inflammatory agents during a disease are known to initiate the reactions of the coagulation cascade and formation of FN-fibrin complexes, which can be easily detected by agarose immunoblotting as a ladder of bands showing molecular masses from 750 to $2200 \mathrm{kDa}$ (Fig. 2). The FN-fibrin complexes occurring in plasma may lead to hypercoagulability, thrombosis, and vessel occlusion [15, 42]. Moreover, the harmful inflammatory agents and age-related processes occurring in arteries provoke ECM remodeling [43], which results from release of ECM components including cellular FN bearing an EDA segment (Fig. 1b). EDA is known to play a significant role in the repair process and in atherosclerosis [9, 26-28].

molecular masses higher than $1000 \mathrm{kDa}$, not observed in the normal plasma or in the samples of patients with mild coronary artery changes, but evidently revealed in the plasma of patients with significant coronary artery changes (Table 2), might be related to increased coagulation. The patients whose plasma revealed such a pattern of FN-fibrin complexes might be suspected of hypercoagulability and high risk of thrombosis, and they should be under special medical care. However, it could not be excluded that the presence of high-molecular FN-fibrin complexes might be bound additionally with severity of coexisting diseases. For example, we have observed the presence of the FNfibrin complexes with molecular masses up to $1900 \mathrm{kDa}$ in the plasma samples of patients with significant coronary artery changes and with acute chest pain, but without medical evidence of acute myocardial infarction. The cluster analysis based on the data of FN-fibrin complexes and EDA-FN levels (Fig. 4) allowed us to separate the subgroup of patients with significant coronary artery changes who should be under special medical care because of high risk of hypercoagulation and thrombosis.

To conclude, the profile analysis of FN-fibrin complexes and the determination of EDA-FN concentration, but not plasma $\mathrm{FN}$ in the plasma of patients, could be considered as a potential diagnostic biomarker helpful in diagnosis, management, and prophylaxis of patients with high risk of atherosclerosis and moreover may help to discriminate the group of patients with high risk of CAD from that with mild risk of CAD.

\section{ACKNOWLEDGMENTS}

We thank Dr Ewa M. Kratz for statistical consultations.

\section{COMPLIANCE WITH ETHICAL STANDARDS}

Patients were included in the study after their clinical evaluation was performed and informed consent had been given. The study was approved by the Bioethical Committee at the Regional Specialist Hospital in Wroclaw and complies with the 1975 Declaration of Helsinki.

Conflict of Interest. The authors declare that they have no competing interests.

Funding Sources. The publication is part of Project "WroVasc - Integrated Cardiovascular Centre" cofinanced by the European Regional Development Fund, within Innovative Economy Operational Program, 20072013, realized in Provincial Specialized Hospital, Research and Development Center in Wroclaw. ("European Fundsfor the development of innovative economy").

Open Access This article is distributed under the terms of the Creative Commons Attribution 4.0 International License (http://creativecommons.org/licenses/by/4.0/), which permits unrestricted use, distribution, and reproduction in any medium, provided you give appropriate credit to the original author(s) and the source, provide a link to the Creative Commons license, and indicate if changes were made.

\section{REFERENCES}

1. Petersen, S., V. Peto, M. Rayner, J. Leal, R. Luengo-Fernandez, and A. Gray. 2005. European cardiovascular disease statistics. London: British Heart Foundation.

2. Hansson, G. 2005. Inflammation, atherosclerosis, and coronary artery disease. The New England Journal of Medicine 16: 1685-95.

3. Frostegård, J. 2013. Immunity, atherosclerosis and cardiovascular disease. BMC Medicine 11: 117.

4. Lim, S., and S. Park. 2014. Role of vascular smooth muscle cell in the inflammation of atherosclerosis. BMB Reports 47: 1-7. 
5. Tabas, I., K.J. Williams, and J. Borén. 2007. Subendothelial lipoprotein retention as the initiating process in atherosclerosis: Update and therapeutic implications. Circulation 16: 1832-44.

6. Didangelos, A., X. Yin, K. Mandal, M. Baumert, M. Jahangiri, and M. Mayr. 2010. Proteomics characterization of extracellular space components in the human aorta. Molecular \& Cellular Proteomics 9: 2048-62.

7. Cromar, G.L., X. Xiong, E. Chautard, S. Ricard-Blum, and J. Parkinson. 2012. Toward a systems level view of the ECM and related proteins: A framework for the systematic definition and analysis of biological systems. Proteins 80: 1522-44.

8. White, E.S., and A.F. Muro. 2011. Fibronectin splice variants: Understanding their multiple roles in health and disease using engineered mouse models. IUBMB Life 63: 538-46.

9. To, W.S., and K.S. Midwood. 2011. Plasma and cellular fibronectin: Distinct and independent functions during tissue repair. Fibrogen Tissue Repair 4: 21.

10. Schwarzbauer, J.E., and D.W. DeSimone. 2011. Fibronectins, their fibrillogenesis, and in vivo functions. Cold Spring Harbor Perspectives in Biology 96: 2588-2590.

11. Hynes, R.O. 1999. The dynamic dialogue between cells and matrices: Implications of fibronectin's elasticity. Proceedings of the National Academy of Sciences USA 6: 2588-90.

12. White, E.S., F.E. Baralle, and A.F. Muro. 2008. New insights into form and function of fibronectin splice variants. Journal of Pathology 216: 1-14.

13. Moretti, F.A., A.K. Chauhan, A. Iaconcig, F. Porro, F.E. Baralle, and A.F. Muro. 2007. A major fraction of fibronectin present in the extracellular matrix of tissues is plasma-derived. The Journal of Biological Chemistry 282: 28057-62.

14. Kostourou, V., and V. Papalazarou. 2014. Non-collagenous ECM proteins in blood vessel morphogenesis and cancer. BBA 1840: 2403-13.

15. Wang, Y., A. Reheman, C.M. Spring, J. Kalantari, A.H. Marshall, A.S. Wolberg, et al. 2014. Plasma fibronectin supports hemostasis and regulates thrombosis. The Journal of Clinical Investigation 10: 4281-93.

16. Maurer, L.M., B.R. Tomasini-Johansson, and D.F. Mosher. 2010. Emerging roles of fibronectin in thrombosis. Thrombosis Research 125: 287-91.

17. Sakai, T., K.J. Johnson, M. Murozono, K. Sakai, M.A. Magnuson, T. Wieloch, et al. 2001. Plasma fibronectin support neuronal survival and reduces brain injury following transient focal cerebral ischemia but is not essential for skin-wound healing and hemostasis. Nature Medicine 7: $324-30$.

18. Tate, C.C., A.J. García, and M.C. LaPlaca. 2007. Plasma fibronectin is neuroprotective following traumatic brain injury. Experimental Neurology 1: 13-22.

19. Makogonenko, E., K.C. Ingham, and L. Medved. 2007. Interaction of the fibronectin $\mathrm{COOH}$ terminal fib-2 regions with fibrin: Further characterization and localization of the fib-2 binding sites. Biochemistry 8: 5418-26.

20. Ramanathan, A., and N. Karuri. 2014. Fibronectin alters the rate of formation and structure of the fibrin matrix. Biochemical and Biophysical Research Communications 443: 395-99.

21. Leiss, M., K. Beckmann, A. Giros, M. Costell, and R. Fassler. 2008. The role of integrin binding sites in fibronectin matrix assembly in vivo. Current Opinion in Cell Biology 20: 502-7.

22. Khan, Z.A., B.M. Chan, S. Uniyal, Y.P. Barbin, H. Farhangkhoee, S. Chen, et al. 2005. EDB fibronectin and angiogenesis-A novel mechanistic pathway. Angiogenesis 8: 183-196.

23. Maurer, E., M. Schaff, N. Receveur, C. Bourdon, L. Mercier, B. Nieswandt, et al. 2015. Fibrillar cellular fibronectin supports efficient platelet aggregation and procoagulant activity. Thrombosis and Haemostasis 114: 1175-88.

24. Cho, J., and D.F. Mosher. 2006. Enhancement of thrombogenesis by plasma fibronectin cross-linked to fibrin and assembled in platelet thrombi. Blood 9: 3555-63.
25. Prakash, P., P.P. Kulkarni, S.R. Lentz, and A.K. Chauhan. 2015. Cellular fibronectin containing extra domain A promotes arterial thrombosis in mice through platelet Toll-like receptor 4. Blood 125: 3164-72.

26. Rohwedder, I., E. Montanez, K. Beckmann, E. Bengtsson, P. Dunér, J. Nilsson, et al. 2012. Plasma fibronectin deficiency impedes atherosclerosis progression and fibrous cap formation. EMBO Molecular Medicine 4: 564-76.

27. Zhang, Y., X. Zhou, J.C. Krepinsky, C. Wang, J. Segbo, and F. Zheng. 2006. Association study between fibronectin and coronary heart disease. Clinical Chemistry and Laboratory Medicine 44: $37-42$.

28. Ozcelik, F., O. Erdogan, M. Aktoz, G. Ekuklu, E. Tatli, and M. Demir. 2009. Diagnostic value of plasma fibronectin level in predicting the presence and severity of coronary artery disease. Annals of Hematology 88: 249-53.

29. Moore, K.J., and E.A. Fisher. 2012. The double-edged sword of fibronectin in atherosclerosis. EMBO Molecular Medicine 4: 561-63.

30. van Keulen, J.K., D.P. de Kleijn, M.M. Nijhuis, E. Busser, E. Velema, R. Fijnheer, et al. 2007. Levels of extra domain A containing fibronectin in human atherosclerotic plaques are associated with a stable plaque phenotype. Atherosclerosis 195: 83-91.

31. PulakazhiVenu, V.K., P. Uboldi, A. Dhyani, A. Patrini, R. Baetta, N. Ferri, et al. 2015. Fibronectin extra domain A stabilises atherosclerotic plaques in apolipoprotein E and in LDL-receptor-deficient mice. Thrombosis and Haemostasis 114: 186-97.

32. Krzyżanowska-Gołąb, D., A. Lemańska-Perek, M. Pupek, K. Lindner, B. Polańska, I. Porębska, et al. 2014. Identification of soluble supramolecular FN-fibrin complexes in human plasma. Journal of Immunoassay and Immunochemistry 35: 412-27.

33. Lemańska-Perek, A., M. Pupek, B. Polańska, J. Leszek, and I. KątnikPrastowska. 2013. Alterations in molecular status of plasma fibronectin associated with aging of normal human individuals. Clinical Biochemistry 46: 787-94.

34. Miszalski-Jamka, T., P. Klimeczek, R. Banyś, M. Krupiński, K. Nycz, K. Bury, et al. 2012. The composition and extent of coronary artery plaque detected by multislice computed tomographic angiography provides incremental prognostic value in patients with suspected coronary artery disease. International Journal of Cardiovascular Imaging 28: 621-31.

35. Pupek, M., D. Krzyżanowska-Gołąb, T. Dyła, A. Lemańska-Perek, R. Jankowska, and I. Katnik-Prastowska. 2009. Presence of highmolecular-weight forms and domain alterations of fibronectin in pleural effusion of patients with lung cancer. Clinical Biochemistry 42: 654-61.

36. Castellanos, M., R. Leira, J. Serena, M. Blanco, S. Pedraza, J. Castillo, et al. 2004. Plasma cellular-fibronectin concentration predicts hemorrhagic transformation after thrombolytic therapy in acute ischemic stroke. Stroke 35: 1671-76.

37. Kanters, S.D., J.D. Banga, A. Algra, R.C. Frijns, J.J. Beutler, and R. Fijnheer. 2001. Plasma levels of cellular fibronectin in diabetes. Diabetes Care 24: 323-27.

38. von $\mathrm{Au}, \mathrm{A}$., M. Vasel, S. Kraft, C. Sens, N. Hackl, A. Marx, et al. 2013. Circulating fibronectin controls tumor growth. NeoPlasia 15: 925-38.

39. Chauhan, A.K., J. Kisucka, M.R. Cozzi, M.T. Walsh, F.A. Moretti, M. Battiston, et al. 2008. Prothrombotic effects of fibronectin isoforms containing the EDA domain. Arteriosclerosis, Thrombosis, and Vascular Biology 28: 296-301.

40. Lemańska-Perek, A., B. Polańska, D. Krzyżanowska-Gołąb, and I. Katnik-Prastowska. 2015. Occurrence of soluble supramolecular FN-fibrin complexes in the plasma of children with 
recurrent respiratory infection. Annals of Clinical Biochemistry 4: 441-47.

41. Pupek, M., R. Pawiłowicz, K. Lindner, D. Krzyżanowska-Gołąb, A. Lemańska-Perek, and B. Panaszek. 2016. Changes in plasma fibronectin molecular status in patients with multimorbidity due to the inflamm-aging phenomenon. Experimental Gerontology 77: 19-28.
42. Wang, Y., and H. Ni. 2015. Fibronectin: Extra domain brings extra risk? Blood 125: 3043-44.

43. Xu, J., and G.P. Shi. 2014. Vascular wall extracellular matrix proteins and vascular disease. Biochimica et Biophysica Acta 1842: 2106-19.

44. Franchini, M. 2006. Hemostasis and aging. Critical Reviews in Oncology/Hematology 60: 144-51. 